\title{
Feasibility Study on Using Passive Infrared Sensor for Wild Pig Repellent System in Bhutan
}

\author{
Chencho $^{1}$, Dechen Lhamo ${ }^{2}$, Kelzang Dorji ${ }^{3}$ \\ ${ }^{1}$ College of Science and Technology, Electronics and Communication Department, Royal University of Bhutan, Bhutan \\ ${ }^{2}$ College of Science and Technology, Electronics and Communication Department, Royal University of Bhutan, Bhutan \\ ${ }^{3}$ College of Science and Technology, Science and Humanities Department, Royal University of Bhutan, Bhutan
}

\begin{abstract}
Every year, farmers in Bhutan lose their crops to wild animals, and it has remained as the same problem over the years. Farmers and Government of Bhutan struggles to get rid of this problem. In the western part of Bhutan, the major crop damage is done by wild pigs. This study was carried out to see the feasibility of using Passive Infrared Sensor (PIR) to protect crops from wild pigs. PIR sensors are motion detector sensors and operates based on the infrared radiation from the body. The sensor has the advantage of low cost, and it is used extensively in indoor automated motion detection systems. All bodies including human emit infrared radiation and the radiation amount depends on body surface temperature. The proposed system consists of a sensing unit, and an alarm unit comprising of a lighting and an audio system. The sensing unit make use of PIR sensor to activate the alarm unit. The audio system is recorded with the sounds that our farmers use to chase away wild pigs during the night hours such as beating of the drums, dog barking etc. The sensor gets activated producing an electrical output which triggers the alarm unit turning ON the light and the audio system.
\end{abstract}

Keywords: Crops, Wild Pig, Feasibility, PIR Sensor, Detection

\section{Background}

Farmers all over Bhutan lose about 18\% [1] of their crops to wild animals every year. Many of the crops were damaged by the elephants in the southern region, and by wild pigs in the western region. The most common and dominant pest in Bhutan is the wild pig. $23 \%$ of farmers in Zhemgang stop growing paddy due to wild pigs [1]. Government rules and regulations regarding the killing of wildlife has made farmers live with the same problem.

The National Post Harvest Centre initiated a study to design and fabricate a wild animal repellent system to lessen the crop damage and burden of night guarding. The system was developed with the focus of protecting crops from wild pigs. An indigenous wild pig repellent was developed based on intermittent production of simultaneous shrill sound with a frequency of $480 \mathrm{~Hz}$, sound pressure of 100 Decibels, acoustic range of $300 \mathrm{~m}$ and a bright lighting system. The main parts of the repellent were electricity supply source, control box, inflorescence bulb and electric horn. Ten sets of repellent were set up at seven different locations in collaboration with interested farmers and concerned Dzongkhag and Gewog extension officers [2].

The first prototype had the problem of light coverage and power consumption. The system was modified to maximize the light coverage range and reduce the power consumption; it consisted of a stationary bulb which could light up only $50 \%$ of the field area. This has let wild pigs to sneak through the darker areas. A second prototype was developed with a rotating device from an electric fan to ensure that the light covered the entire area. However, after installation of second prototype in different parts of the country, high power fluctuation, insufficient amperage and extremely high relative humidity that is prevalent during the maize maturity and paddy transplantation stage, were noticed. These problems made the device to malfunction occasionally.

To overcome these problems, another prototype was developed consisting of an inflorescent bulb and an electric fan; while other parts like timer, auxiliary contactor and electric blower were removed from the earlier prototype. Though this prototype worked better than the earlier ones, the switched mode power supply in this prototype was found to be very sensitive to humidity. Nevertheless, the electric horn lasted for only 3 to 4 months [2].

Electric fence is another solution. Fences are most effective against wild pigs. At present, the agriculture ministry has adopted the use of electric fences, fabricated with specific energizer provided by Bhutan Electricity Authority (BEA) on a trial basis. However, the use of this method could be expensive and probably not affordable. Bhutan National Human-Wildlife Conflict Management Strategy (2008), gives the following ways to resolve Human- Wild Pig Conflict.

- Allow wild pigs to return to the forest Population control (e.g., culling in hot spot areas, contraceptive control, etc.).

- Create clean buffer zones between the forest and agriculture fields.

- Allow free culling within farm lands and consider 'killzones' up to a distance of $500 \mathrm{~m}$.

- Provide subsidy for fencing materials.

- Compensate total loss of crops (e.g. With food grains, seeds, etc.).

- Provide technical assistance for culling and other treatments.

\section{Volume 6 Issue 12, December 2017}




\section{International Journal of Science and Research (IJSR) \\ ISSN (Online): 2319-7064}

Index Copernicus Value (2016): 79.57 | Impact Factor (2015): 6.391

- Establish community volunteers to monitor fields at critical periods during the growing seasons.

- Allow interested people to hunt under licenses and permission.

- Promote predator numbers especially wild dogs.

- Awareness and training for farmers.

- Create a Wild Pig Response Team.

- On farm adaptive research

However, it would be very difficult to implement these strategies because implementing these strategies would either cost a huge sum to the government if the damage is severe or it will lead to loss of lives of wild pigs. Therefore, an alternative solution is required which is economical and both crops and pigs can be saved.

\section{Introduction}

This project was carried out to see the feasibility of using Passive Infrared Sensor to protect crops from the wild pigs. The sensor works well for the indoor automated application. The advantage of using this sensor is low power consumption and its low cost. PIR sensor is used in many applications, especially in automated systems. An automated low cost security system [3] was developed using PIR sensor; the system performance was found to be good for the purpose but it was used for the indoor application. The whole concept of the system was based on the detection of infrared radiation from the intruder by the PIR Sensor; the sensor output was then used to turn ON the recording system. The system was designed to operate when the intruders (human) come within the detection range of the PIR sensor. Typical human body temperature is $37^{\circ} \mathrm{C}$ and it may be $1^{\circ} \mathrm{C}$ above or below [4][5]. All objects emit infrared, and the amount of radiation can depend on body surface temperature [6]. The body temperature of wild pig is greater than a human body. It was felt that the same concept could be applied to design a safe and, low cost wild pig repellent device.

Figure 1. is the block diagram representation of the first prototype designed using PIR sensor. PIR sensor is a thermal detector. It can measure incident radiation by means of change in the temperature [7]. The sensor was designed to detect an intruder emitting radiation with wavelength of the 8-14 $\mu \mathrm{m}$ [7]. It requires an input of $5 \mathrm{~V} \mathrm{DC}$. The system has three main units; detection(sensing), sound and lighting. In brief, the system works in the following order:

- The detection unit has the PIR sensors and other circuitry for the sensing when the intruder (wild pig) is within the detection range of the sensor.

- The output from the detection unit is used for activating the relays to actuate a lighting and sound unit.

- When the object is not within the detection range of the sensor, no output is produced. Therefore, the lighting and the sound/alarm unit remain OFF consuming no power.

Wild pigs are insensitive to red and green light but sensitive to bright light [8]. White outdoor flood light (Light Emitting Diode) of $10 \mathrm{~W}$ was selected for this reason. The sound system used is an mp3 player with speakers. The mp3 player is recorded with the sounds of dogs barking, beating of empty drums, a man shouting and tiger roaring. Multiple sounds were used so that the wild pig would not get familiar with one sound. These sounds were selected based on an informal talk with the farmers on how they chase away wild animals at night. The sound of tiger roaring was used since it was broadcasted on the Bhutan Broadcasting Service (BBS) that the farmers use tiger dolls to protect the crops.

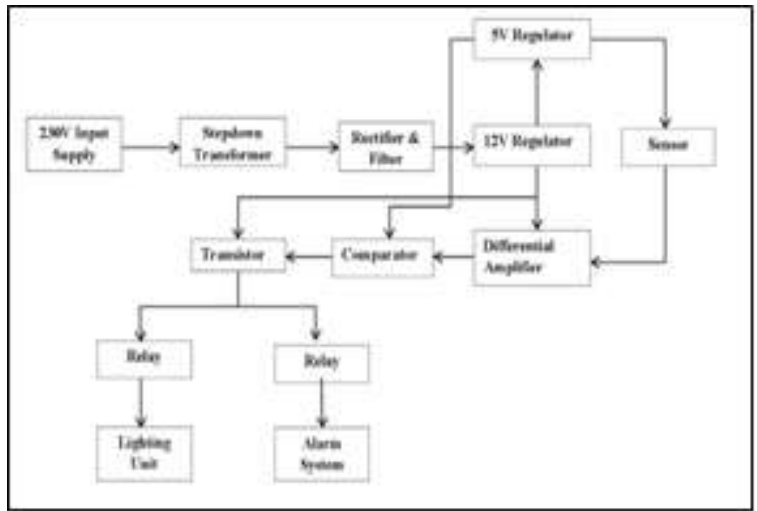

Figure 1: Block diagram of proposed system

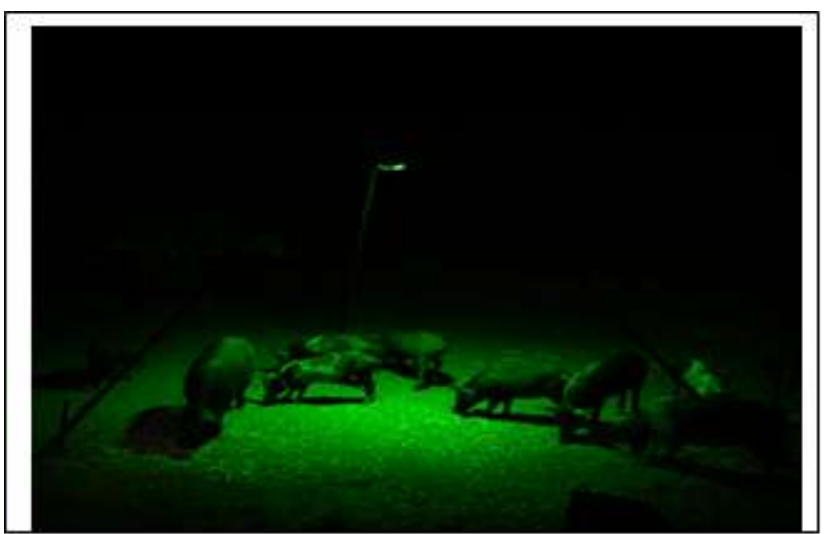

Figure 2a: Wild pigs insensitive to green light; hunters spread grains on the ground and use these light to see them in dark (Image: Elusive Wildlife Technologies, 2017, https://elusivewildlife.com/shop/kill-light-feeder-light.html)

\section{Laboratory Testing and Limitation}

Some limitations were discovered during the lab testing of the designed system. The primary power source for the system is a single phase $230 \mathrm{~V}$, AC. This source is stepped down and rectified to obtain required power supplies for the internal circuits. The primary source either needs to be tapped from an electric pole or the residents nearby the field. A long length electric wire is required if the field is far away from the electric pole or the residents. To overcome this problem, the system was modified replacing the ac power source with a $12 \mathrm{~V}$ DC battery and $10 \mathrm{~W}$ flood lighting (Light Emitting Diode) with 12V DC input.

\section{System Positioning and Field Testing}

The field testing was done at Rangri Chunku, Kabji Gewong, Punakha district. Figure 3. (a) \& (b) shows the

\section{Volume 6 Issue 12, December 2017}




\section{International Journal of Science and Research (IJSR) \\ ISSN (Online): 2319-7064}

Index Copernicus Value (2016): 79.57 | Impact Factor (2015): 6.391

picture of a paddy field surrounded by forest where the system was tested. While trying to install the system, it was observed that the field borders need to be considered; there were two cases, one with its border shared with the forest, and other sharing with the uncultivated field. The uncultivated field border extents to the forest. The red colour line in Figure 3. (a) and (b) shows the field borders.

The detection range of the PIR sensor used in the study is 7 meters maximum. The sensor has some delay in activating the lighting and sound system after it gets activated. If all three units (detection, light and sound) are placed at the field border, there is a possibility that the lighting and sound system gets turned ON when the wild pig reach or cross the border; this might chase them towards the field. For this reason, the systems were installed as shown in the Figure 4. The sound and light units were placed at the field border, and detection unit (sensor) at some distance away from the field border. The sensor gets activated when the wild pigs is within $7 \mathrm{~m}$ from the sensor. The output generated from the sensor turns ON the light and mp3 before the wild pigs reach the field border. This could chase them back to the forest.

Three prototypes were developed and tested at site which were placed at different points of the field. The testing was carried out on 9th November, 2015 for a day and night. Paddy harvesting season was almost over and only few paddy fields were not harvested. The site was told to be damaged mainly by the wild pigs and monkeys.

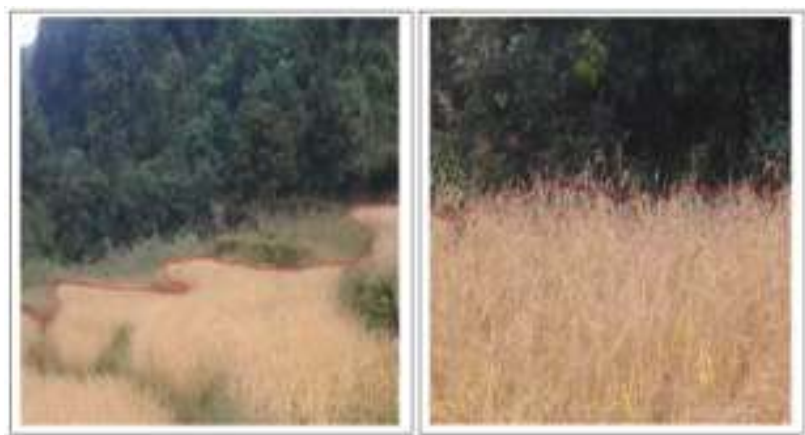

Figure 3: (a) Field Border sharing with uncultivated land (b) Field Border sharing with forest

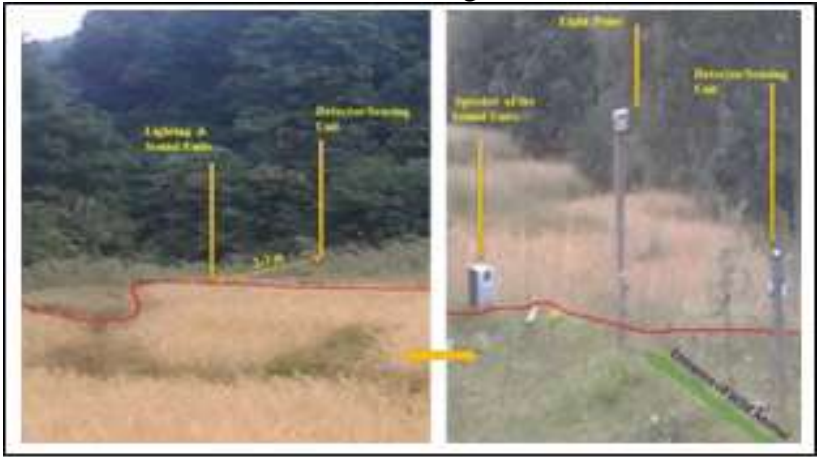

Figure 4: System Positioning

\section{Findings}

During the installation and testing, it was found that:

1) The sensor has a maximum read range of 7 meters and makes the system suitable for very small area. The system can also be used where there is single entry for the wild pigs into the field. It cannot be used in a large field due to its detection range. For a large field, more systems should be placed at different places.

2) The system requires a light point and a sound system each. The overall cost will become expensive if the land size is large.

3) The light and sound gets turned off as soon as the intruder leaves the detection range of the sensor. This was found out during the day time testing when a nearby cow visited the field. It runs away hearing the sound and takes less than 5 seconds to cross the detection range of the sensor. Once it crosses the detection range, the system gets turned, and the cow get back again activating the system. This can increase the power consumption. Further modifications in the circuit was made to overcome this problem as shown in figure 5. A timer was used in the circuit to keep the sound and light turned on for a longer duration (15-20 seconds) when it gets activated. The window comparator was also removed after it was found that the required output from the sensor was obtained every time the sensor gets activated. The modified system working remains same except that the system gets turned on for longer duration when there is an intruder. No wild pigs and monkeys were observed during the testing time but it was found that the system worked well for the cows during the day time.

\section{Discussion and Analysis}

The system developed is effective for the small cultivated land and with one entry point to the field. The sensor detection range is less than seven meters. To protect a large cultivated land, several systems should be installed and this can increase the overall cost. The system was tested with the human body and a cow which has the temperature of 37 Degree Celsius [9] and 38.6 Degree Celsius[10] respectively. However, the body temperature of wild pigs was found to be 39.3 Degree Celsius [11]. The system works on the principle of infrared radiation. All the object emits infrared radiation including human body. The amount of radiation depends on the surface temperature of the object [12]. The system worked well with the human and a cow. The body temperature of the wild pig is more than the body temperature of human and cow. The thermal radiation from the wild pig will be more and system can get activated when it enters the detection range of the system. The system was tested in Punakha in the month of November when the weather was warm and humidity was low. There is a possibility of electronic components of the system being damaged by the humidity during summer in hot places.

Volume 6 Issue 12, December 2017 


\section{International Journal of Science and Research (IJSR) \\ ISSN (Online): 2319-7064}

Index Copernicus Value (2016): 79.57 | Impact Factor (2015): 6.391

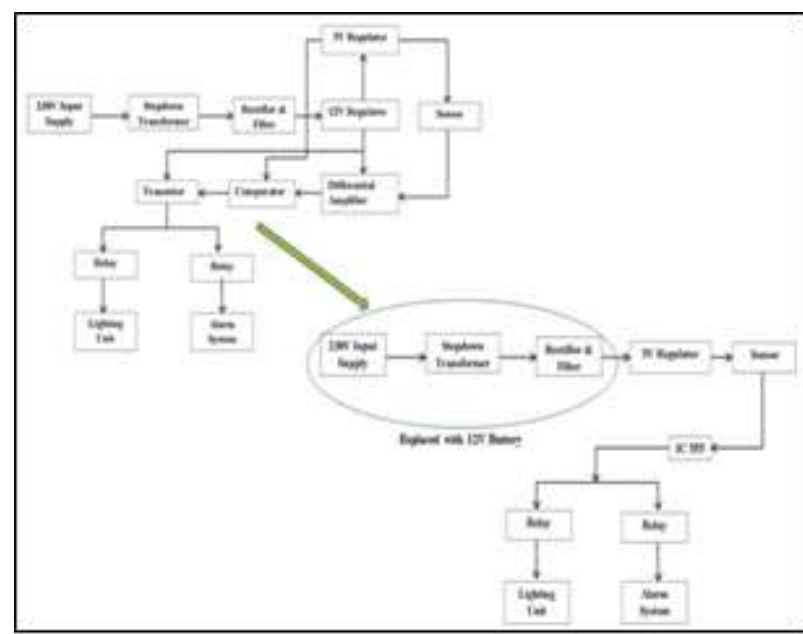

\section{Conclusion}

The system designed was tested and found that it can be used for a small cultivated land. The system was actually designed to chase away wild pigs but during testing day, no pigs turned out. The system worked well with cow which has its body temperature less than the wild pigs. The radiation depends on the body temperature; higher the body temperature, more the radiation. The system will work for pigs as well because the radiation from the pig will be more than a cow. The sensing unit in the system is the important unit which operates based on the radiation from body. It can generate output as long as it is exposed to radiation. Its output activates the other units. However, there is still need to explore for the improvement in the system to make it suitable for a large cultivated land.

\section{Future Work}

From the findings of the study, there is a need to carry out another study to save the overall cost of the system either by using sensor with long detection range or by using single lighting and sound system with more power to cover large area. This can replace several sensors of short detection range, lighting, and sound system. It might require the use of other wireless devices to transmit signals from sensing/detection unit to alarm unit (lighting and sound).

\section{Acknowledgment}

The study was supported by Royal University of Bhutan through Annual University Research Grant (AURG).

\section{References}

[1] Nature Conservation Division, Department of Forestry, Ministry of Agriculture, 2009, " Bhutan National Human- Wildlife Conflict Management Strategies, Chapter 4: Resolving Human- Wild Pig Conflict",

[2] Dakpa, P., Penjor, U., \& Dorji, T., 2009. Design Fabrication and Performance evaluation of wild pig repellent device. Renewable natural resources of Bhutan-Livestocks, vol.5, no1, pp.116-126.

[3] Choden et al. (2013). Passive Infrared Sensor (PIR). International Journal of Electrical, Electronics and Computer Systems. 14(2)
[4] Body Temperature., (1994). Academic American Encyclopedia. New York: American Encyclopedia, 1994: B 357.

[5] Body Temperature., (2014). Retrieved from http://www.webmd.com/first-aid/body-temperature

[6] Netting, Ruth. (2008). The Electromagnetic Spectrum. Retrieved $25^{\text {th }} \quad$ June, 2016 from http://science.hq.nasa.gov/kids/imagers/ems/infrared.ht $\mathrm{ml}$

[7] Zappi, P., Farella, E., \& Benini, L. (2008). Tracking motion direction and distance with Pyroelectric InfraRed Sensors. IEEE Sensor Journal Class Files.

[8] Masson, Todd. (2014). Hog hunter targets big pigs at night with light bait. Retrieved 25th June, 2016, from http://www.nola.com/outdoors/index.ssf/2014/02/hog_hu nter_targets_big_pigs_at.html

[9] Campbell, Neil A. Biology. 3rd ed. California: Benjamin Cummings, 1987: 790.

[10] MacDonald, David. Mammals. Oxford: Equinox, 1984: 545.

[11] Goulding, M.J. (2005) Wild Boar. Biological Sciences Review, 17, (4) 9-11.

[12] Ming, L.Shuk., Olivia (2010). Radiation emitted by Human Body Thermal Radiation http://www.hko.gov.hk/prtver/pdf/docs/education/edu02r ga/radiation/radiation_02-e.pdf 